\title{
A Study of Clinical Profile and Complications In Patients with ST-Elevation Myocardial Infarction Attending In College of Medical Sciences Teaching Hospital, Bharatpur (Chitwan), Nepal.
}

\author{
Pradeep Thapa ${ }^{1}$, Prakash Aryal$^{1}$, Rajani Baniya ${ }^{2}$.
}

${ }^{1}$ Department of Internal Medicine, College of Medical Sciences, Bharatpur.

${ }^{2}$ BP Smriti Hospital, Kathmandu.

Corresponding Author:

Pradeep Thapa

Department of Internal Medicine, College of Medical Sciences, Bharatpur, Chitwan.

Email: pradeep thapa69@hotmail.com

ORCID ID: https://orcid.org/0000-0002-5072-183X

Cite this article as: Thapa P, Aryal P, Baniya R, A Study of Clinical Profile and Complications In Patients with ST-Elevation Myocardial Infarction Attending In College of Medical Sciences Teaching Hospital, Bharatpur (Chitwan), Nepal. Nepalese Heart Journal 2021; Vol 18 (1): 33-37.

Submitted date: $7^{\text {th }}$ July 2020

Accepted date: $8^{\text {th }}$ February 2021

\section{Abstract}

Background and Aims: ST-Elevation Myocardial Infarction (STEMI) is a leading cause of morbidity and mortality. This study aims to summarize the clinical profile and complications of patients with STEMI in a teaching hospital.

Methods: This was a prospective hospital based descriptive and observational study conducted at College of Medical Sciences Teaching Hospital (CoMSTH), Bharatpur from January 2017 to July 2018 in 110 patients with a diagnosis of acute STEMI.

Results: Out of 110 patients the mean age of presentation was 59.31 years and $64.5 \%$ were male. Typical chest pain (90\%) was the most common presenting symptom and $45.5 \%$ patients presented within six hours of chest pain. Most common traditional risk factors were hypertension and smoking which were present in $44(40 \%)$ cases, followed by diabetes in 33 (30\%), dyslipidemia in $22(20 \%)$. Majority of patients (49.1\%) were in killips class I, and only $9(8.2 \%)$ patients were in cardiogenic shock (killips class IV). Inferior wall was the most common in $30 \%$ patients followed by anteroseptal wall MI (23.6\%), anterior wall MI (11.8\%) and combined (anterior and inferior) in 10\%. Revascularization with primary Percutaneous Coronary Intervention (PCI) was done in $46(41.8 \%)$ patients, thrombolysis was done in $41(37.3 \%)$ patients. Arrhythmias (39.1\%) followed by heart failure (24.5\%) were the common complications. The overall in-hospital mortality was $16(14.5 \%)$. Conclusions: Patients with acute STEMI at College of Medical Sciences Teaching Hospital (CoMSTH) were predominantly male with hypertension and smoking as the commonest risk factors. Arrhythmias were the most common complications and in-hospital mortality rate was $14.5 \%$.

Keywords: Acute ST Elevation Myocardial Infarction; Percutaneous Coronary Intervention; Thrombolysis.

DOI: https://orcid.org/10.3126/njh.v18i1.36782

\section{Background}

Coronary Artery Disease (CAD) is the common heart disease in Nepal with prevalence of $5.7 \% .{ }^{1}$ Myocardial infarction was more common in older population, however its incidence in young has been increasing. ${ }^{2}$ Early detection and creating awareness regarding risk factors help to prevent mortality and morbidity. ${ }^{3}$
The introduction of coronary care units decreased Acute Myocardial Infarction (AMI) mortality from $30 \%$ to $15 \%,{ }^{4}$ while with broad application of reperfusion therapy for ST-Elevation Myocardial Infarction (STEMI) 30 day mortality rates have progressively declined to less than $5 \% .^{5}$ The mortality due to STEMI in the developing countries like Nepal is still high due to poor access

(a) Nepalese Heart Journal. Nepalese Heart Journal retain copyright and works is simultaneously licensed under Creative Commons Attribution License CC - By 4.0 that allows others to share the work with an acknowledge of the work's authorship and initial publication in this journal 
to health facilities. Most of the tertiary care hospitals with facilities for percutaneous coronary interventions in Nepal are located mainly in few cities.

This study aimed at knowing the clinical profile, complications and its outcome in STEMI patients who presented to College of Medical Sciences and Teaching Hospital, Bharatpur with STEMI.

\section{Methods}

This was a hospital based prospective observational, descriptive study conducted at College of Medical Sciences and Teaching hospital (CoMSTH), Bharatpur, Nepal from January 2017 to July 2018.

Ethical clearance was taken from the Ethical Committee of CoMSTH. Informed signed consent was taken from each respondent or their relative. Non-probability convenience sampling technique was employed. Considering the prevalence of CAD in Nepal to be $5.7 \%,{ }^{1}$ sample size was calculated to be 83 as per the formula. $\mathrm{n}=\mathrm{Z}^{2} \mathrm{pq} / \mathrm{E}^{2}$ Where: $\mathrm{Z}=1.96$ (for $95 \%$ confidence interval): $\mathrm{p}=0.057$, $\mathrm{q}=1-\mathrm{p}, \mathrm{e}=0.05$ (allowable error of $5 \%$ ).

One hundred and ten patients diagnosed as acute STEMI with age $>18$ years were included in the study. Non ST elevation myocardial infarction and history of myocardial infarction in the past were excluded.

Study parameters including demographic variables, history of traditional risk factors (age, sex, smoking, dyslipidemia, diabetes, hypertension, and family history), clinical presentation, complications and in-hospital outcomes were recorded. Patient with acute STEMI were evaluated clinically and investigated with electrocardiograph, echocardiography, cardiac markers and coronary angiography (whenever required). Other relevant investigations were done to rule out other co-morbidities.

Acute STEMI was defined as chest pain of $>20$ min duration and ST segment elevation $>1 \mathrm{~mm}$ in at least two contiguous precordial standard limbs leads or $>2 \mathrm{~mm}$ in at least two contiguous precordial leads presented within 7 days of symptoms with positive cardiac biomarkers.

Hypertension was defined as diagnosed case on medication or lifestyle modification or based on the definition by the seventh report of the Joint National Committee. ${ }^{6}$

Diabetes was defined as diagnosed case on medication or lifestyle modification or was diagnosed as American Diabetes Association (ADA). ${ }^{7}$

Dyslipidemia was defined as diagnosed case on medication or lifestyle modification or if fasting low density lipoprotein cholesterol $\geq$ $140 \mathrm{mg} / \mathrm{dL}$ or high density lipoprotein cholesterol $<40 \mathrm{mg} / \mathrm{dL}$ or triglyceride $\geq 150 \mathrm{mg} / \mathrm{dL}^{8}{ }^{8}$

Smoker was defined as a person who had smoked at least 100 cigarettes in lifetime and is continuing smoking (current smoker) or had quit at the time of interview (former smoker) ${ }^{9}$

Family history of premature coronary artery disease was defined as first degree relatives who had coronary artery disease before 55 years in male and 65 years in female.

All the patients received routine anti-ischemic therapy, followed by revascularisation with either primary PCI or thrombolysis and routine post MI management. Complications and outcomes were evaluated by electrocardiograph, echocardiograph and other investigations when ever required.

The data obtained by history, clinical examination and investigations was entered to the computer system using SPSS version 20.0 software and analyzed. Descriptive statistics were used to describe the data. Results were expressed in frequencies and percentages.

\section{Results}

Out of total 110 patients, $71(64.5 \%)$ were male and $39(35.5 \%)$ were female. The incidence of AMI was found to be highest in the age group of 51-60 years $(29.1 \%)$ with the mean age of 59.31 years as shown in table 1 . There were total of $12(7.1 \%)$ cases below the age of 45 years.

Table 1: Age distribution of the patients.

\begin{tabular}{|c|c|c|}
\hline Age Group & No. of Patients & Percentage $(\%)$ \\
\hline $31-40$ & 7 & 6.4 \\
\hline $41-50$ & 21 & 19 \\
\hline $51-60$ & 32 & 29.1 \\
\hline $61-70$ & 28 & 25.5 \\
\hline $71-80$ & 20 & 18.2 \\
\hline$>80$ & 2 & 1.8 \\
\hline
\end{tabular}

The chest pain was typical in 100 (90.9\%) cases and atypical chest pain was present in $10(9.1 \%)$ patients. This study showed, sweating $42(38.2 \%)$ with chest pain as the most common presenting symptom followed by dyspnoea 39 (35.5\%), nausea and vomiting 25 (22.7\%), palpitation $13(11.8 \%)$ and epigastric pain $10(9.1 \%)$ as shown in table 2 .

Table 2: Associated symptoms among patients.

\begin{tabular}{|c|c|c|}
\hline $\begin{array}{l}\text { Associated } \\
\text { Symptoms }\end{array}$ & No. of Patients & Percentage (\%) \\
\hline Dyspnoea & 39 & 35.5 \\
\hline Nausea and Vomiting & 25 & 22.7 \\
\hline Palpitations & 13 & 11.8 \\
\hline Sweating & 42 & 38.2 \\
\hline Epigastric Pain & 10 & 9.1 \\
\hline
\end{tabular}

Almost half of the patients $(45.5 \%)$ were brought to the hospital within 6 hours of onset of symptoms followed by $31.8 \%$ within 6 to 12 hour as shown in table 3.

Table 3: Duration of chest pain before arrival to the hospital.

\begin{tabular}{|c|c|c|}
\hline Time of Presentations & No. of Patients & Percentage $(\%)$ \\
\hline$<6$ Hours & 50 & 45.5 \\
\hline 6 to 12 Hours & 35 & 31.8 \\
\hline 12 to 24 Hours & 6 & 5.5 \\
\hline$>24$ Hours & 19 & 17.2 \\
\hline
\end{tabular}

In this study, smoking and hypertension were present in $44(40 \%)$ patients as a most coronary artery disease (CAD) risk factors followed by diabetes $33(30 \%)$, alcohol $33(30 \%)$, dyslipidemia $22(20 \%)$ and family history of Ischemic Heart Disease (IHD) 7 (6.4\%) as shown in table 4 . 
Table 4: CAD risk factors.

\begin{tabular}{|c|c|c|}
\hline CAD Risk Factors & No. of Patients & Percentage $(\%)$ \\
\hline Smoking & 44 & 40 \\
\hline Alcohol & 33 & 30 \\
\hline Hypertension & 44 & 40 \\
\hline Diabetes & 33 & 30 \\
\hline Dyslipidemia & 22 & 20 \\
\hline Family History & 7 & 6.4 \\
\hline
\end{tabular}

Majority of patients (49.1\%) were under Killip's class I (table 5) Inferior wall was the most common in $33(30 \%)$ patients followed by anteroseptal MI 26 (23.6\%), anterior wall MI $13(11.8 \%)$ and combined (anterior and inferior) in $11(10 \%)$ patients as shown in table 6.

Table 5: Distribution of patients according to severity of the disease.

\begin{tabular}{|lll|}
\hline Killip's Class & No. of Patients & Percentage (\%) \\
\hline I & 54 & 49.1 \\
\hline II & 35 & 31.8 \\
\hline III & 12 & 10.9 \\
\hline IV & 9 & 8.2 \\
\hline
\end{tabular}

Table 6: Site of infarction as per the ECG findings.

\begin{tabular}{|c|c|c|}
\hline Site of Infarction & No. of Patients & $\begin{array}{l}\text { Percentage } \\
(\%)\end{array}$ \\
\hline Anteroseptal MI & 26 & 23.6 \\
\hline Anterolateral & 11 & 10 \\
\hline Anterior Wall MI & 13 & 11.8 \\
\hline Extensive Anterior Wall MI & 8 & 7.3 \\
\hline Inferior Wall MI & 33 & 30 \\
\hline Infero-Lateral MI & 8 & 7.3 \\
\hline $\begin{array}{l}\text { Combined (Anterior and } \\
\text { Inferior) MI }\end{array}$ & 11 & 10 \\
\hline
\end{tabular}

Out of 110 patients, primary Percutaneous Coronary Intervention (PCI) was done in $46(42.7 \%)$ cases, 41 (37.3\%) were thrombolysed and no revascularisation was done in $23(20.9 \%)$ patients as shown in table 7 .
Table 7: Rescularization by PCI/thrombolysis.

\begin{tabular}{|lll|}
\hline Revascularisation & No. of Patients & Percentage (\%) \\
\hline Thrombolysed & 41 & 37.3 \\
\hline PCI & 46 & 41.8 \\
\hline None & 23 & 20.9 \\
\hline
\end{tabular}

The most common complication seen was arrhythmia in 43 (39.1\%) patients followed by heart failure in 27 (24.5\%). Cerebrovascular accidents were seen in $4(3.6 \%)$ cases, pericarditis in $2(1.8 \%)$ and papillary muscle rupture in $8(7.3 \%)$ as shown in table 8 . The overall in-hospital mortality was $14.5 \%$.

Table 8: Complications of ST Elevation Myocardial Infarction.

\begin{tabular}{|lll|}
\hline Complication & No. of Patients & Percentage (\%) \\
\hline Arrythmia & 43 & 39.1 \\
\hline Heart Failure & 27 & 24.5 \\
\hline Pericarditis & 2 & 1.8 \\
\hline Cerebrovascular Accidents & 4 & 3.6 \\
\hline Papillary Muscle Rupture & 8 & 7.3 \\
\hline
\end{tabular}

\section{Discussion}

In the present study of a total of 110 patients $71(64.5 \%)$ were male and $39(35.5 \%)$ were female. Shahid Gangalal National Heart Centre STEMI registry (2020) showed that $70 \%$ were male. ${ }^{10}$

The incidence of acute myocardial infarction was found to be highest in age group of 51-60 years $(29.1 \%)$ while lowest among age group of $31-40(6.4 \%)$ and above $80(1.8 \%)$ years while $7.1 \%$ were less than 45 years. The mean age of presentation was 59.31 years which is consistent with many other studies, Dhungel et al. $(60.05 \pm 12.2$ years $),{ }^{11}$ SGNHC-STEMI-registry $(60.8 \pm 13.4 \text { years })^{10}$ and Hafeez et al. (58 \pm 11 years). ${ }^{12}$ The incidence of MI in young patients $\left(<45\right.$ years) ranges from $6 \%-10 \%{ }^{13}$

Hypertension and smoking were present in $44(40 \%)$ patients which was the most common coronary risk factor followed by diabetes $33(30 \%)$, alcohol $33(30 \%)$, dyslipidemia $22(20 \%)$ and family history of IHD 7 (6.4\%). SGNHC-STEMI-registry showed smoking as the most common risk factor (54\%) followed by hypertension (36.6\%). Hypertension was found in $65 \%$ of patients in study done by Adhikari et al. ${ }^{14}$ Smoking was present as a most common risk factor as seen in studies done by Dhungel et al. ${ }^{11}(87.7 \%)$, Gautam et al. ${ }^{15}(50.8 \%)$ and Shrestha et al. ${ }^{16}$ $(60 \%)$. Findings were also similar to study done by Misiriya et al. ${ }^{17}$ in India in which most common risk factor was smoking $46.6 \%$, followed by hypertension $29.02 \%$, dyslipidemia $26.15 \%$, diabetes mellitus $23.95 \%$.

In present study $33(30 \%)$ of the patients had diabetes which was comparable with studies done by Adhikari et al. ${ }^{14}(31 \%)$. In other studies prevalence of diabetes varies from $12.7 \%$ to $43.51 \%$. In our study $20 \%$ patients had dyslipidemia which was similar with study of 
Dhungel et al. ${ }^{11}(25.3 \%)$, Gautam et al. $^{15}(26.3 \%)$ and Misiriya et al. ${ }^{17}(26.15 \%)$.

In our study hypertension and smoking were most common risk factors associated with acute myocardial infarction which was similar to other studies done in India and western countries.

Typical chest pain was the most common symptom at presentation $(90.9 \%)$ which was consistent with other studies like Hafeez et al. (94\%) and Gupta et al. (81.8\%). Chest pain was most commonly associated with sweating $(38.2 \%)$ followed by dyspnoea $(35.5 \%)$, nausea and vomiting $(22.7 \%)$, palpitation (11.8\%) and epigastric pain $(9.1 \%)$ in our study which were also noted in study done by Shrestha et al. ${ }^{16}$

Anterior wall MI was present in $58(52.7 \%)$ and inferior wall MI in $41(37.3 \%)$ patients in this study. Study done by Adhikari et al. ${ }^{19}$ showed anterior wall MI to be present in $52.94 \%$ and inferior wall in $41.17 \%$ cases. In a study by Vaidya et al. ${ }^{20} 42.5 \%$ had anterior wall and $31.4 \%$ had inferior wall MI. Hafeez et al. ${ }^{12}$ reported acute MI to involve inferior wall in $46 \%$, anterior wall in $30 \%$.

Out of 110 patients, $46(41.8 \%)$ patients underwent primary PCI and $41(37.3 \%)$ patients were thrombolysed while 23 patients didn't receive any reperfusion therapy in our study. SGNHC-STEMIRegistry showed that only around $32.7 \%$ cases received reperfusion therapy with $80 \%$ underwent primary angioplasty and $20 \%$ were thrombolysed.

The most common complication present in our study was arrythmia (39.1\%). In a study done by Singh et al. (2013) ${ }^{18}$ arrhythmia was present in $50 \%$ cases which was consistent to our present study, cardiac failure in $40 \%$, cerebrovascular accident in $6 \%$ and mechanical complications (ventricular septal defect, mitral regurgitation and papillary muscle dysfunction) in $4 \%$ patients. Similarly, study done by Vaidya et al. $(2015)^{20}$ showed arrhythmias in $24.6 \%$ and $60 \%$ in Yadav et al. (2010) ${ }^{21}$ Heart failure occurred in $27(24.5 \%)$ patients which was comparable to studies done by Vaidya et al. $20(10.9 \%)$ and Pathak et al. ${ }^{22}(13.74 \%)$. Similarly, papillary muscle rupture was present in 8 (7.3\%), pericarditis was observed in only $2(1.8 \%)$ cases and cerebrovascular accidents were observed in $4(3.6 \%)$ cases which was comparable with studies done by Yadav et al. ${ }^{21}(2.5 \%)$ and Kundu et al. ${ }^{23}(2.3 \%)$.

In this study, $16(14.5 \%)$ patients died in hospital which was in consistent with various studies by Shrestha et al. ${ }^{16}$, Vaidya et al. (2015), ${ }^{20}$ Pathak et al. (2015) ${ }^{22}$ and Kundu et al. (1982). ${ }^{23}$ An overall in hospital mortality in our study was $14.5 \%$ which was higher than generally reported by Global Registry of Acute Coronary Events (GRACE) for STEMI $(7 \%){ }^{24}$ This may be due to the fact that our hospital being a referral centre, we received proportionately more number of critically ill and sick patients with late presentation from peripheral hospitals of Eastern and Western part of Nepal.

\section{Limitations}

Small sample size is the limitation of this study. Due to limited follow up in the post MI period, we could only record in-hospital outcomes, which might vary with use of standardized time frame.

\section{Conclusion}

This observational study of STEMI patients presented to CoMSTH has confirmed the established facts regarding risk factors, common age groups and clinical presentations of STEMI. Majority of patients $(45.5 \%)$ presented to the hospital within 6 hours of chest pain and anterior wall MI was the most common. Significant number of patients received reperfusion therapy and overall in-hospital mortality was $14.5 \%$ which is higher than general. Arrythmia was the major complications, present in $39.1 \%$ of patients.

\section{Conflict of Interest: None Source of Funding: None}

Acknowledgement: Authors are grateful to all the patients who consented for the study and department of cardiology for all the help.

\section{References}

1. Vaidya A, Pokharel PK, Nagesh S, et al. Prevalence of coronary heart disease in the urban adult males of eastern Nepal: a population-based analytical cross-sectional study. Indian Heart J. 2009;61(4):341-7.

http://www.ncbi.nlm.nih.gov/pubmed/20635736

2. Egred M, Myocardial infarction in young adults. Postgrad Med J. 2005 Dec 1;81(962):741-5.

https://doi.org/10.1136/pgmj.2004.027532

3. Seetharama N, Mahalingappa R, GK RK, et al. Clinical profile of acute myocardial infarction patients: a study in tertiary care centre. Int J Res Med Sci. 2015 Feb;3(2):412-419. https://doi.org/10.5455/2320-6012.ijrms20150206

4. GUSTO Angiographic Investigators. The effects of tissue plasminogen activator, streptokinase, or both on coronaryartery patency, ventricular function, and survival after acute myocardial infarction. N Engl J Med.1993 Nov 25;329(22):1615-22. https://doi.org/10.1056/NEJM199311253292204

5. Anderson JL, Morrow DA, Acute Myocardial Infarction. N Engl J Med. 2017 May;376(21):2053-64. https://doi.org/10.1056/NEJMra1606915

6. Chobanian A V, Bakris GL, Black HR, et al. Seventh report of the Joint National Committee on Prevention, Detection, Evaluation, and Treatment of High Blood Pressure. Hypertens (Dallas, Tex 1979). 2003 Dec;42(6):1206-52. https://doi.org/10.1161/01.HYP.0000107251.49515.c2

7. Diagnosis and classification of diabetes mellitus. Diabetes Care. 2009 Jan;32 Suppl 1(Suppl 1):S62-7. https://doi.org/10.2337/dc09-S062

8. Teramoto T, Sasaki J, Ishibashi S, et al. Diagnostic Criteria for Dyslipidemia. J Atheroscler Thromb. 2013;20(8):655-60. https://doi.org/10.5551/jat.17152

9. NHIS-Adult Tobacco Use-Glossary [Internet] Centers Dis Control Prev (CDC) Available from https//www.cdc.gov/nchs/ nhis/tobacco/tobacco glossary. html. No Title. https://www.cdc.gov/nchs/nhis/tobacco/tobacco_glossary.html

10. Adhikari CM, Acharya KP, Manandhar R, et al. Shahid Gangalal National Heart Centre-ST-elevation Myocardial infarction Registry (SGNHC-STEMI-Registry), Nepal. Nepal Hear J. 2020 May 6;17(1):7-16. https://doi.org/10.3126/njh.v17i1.28795

11. Dhungel S, Laudari S, Dubey L, et al. Risk factors for ST- Elevation Myocardial Infarction in a tertiary hospital in central Nepal. J Coll Med Sci. 2017 Dec 20;13(4):416-9. https://doi.org/10.3126/jcmsn.v13i4.18615 
12. Hafeez S, Javed A, Kayani AM. Clinical profile of patients presenting with acute ST elevation myocardial infarction. J Pak Med Assoc. 2010 Mar;60(3):190-3. http://www.ncbi.nlm.nih.gov/pubmed/20225775

13. Choudhury L, Marsh JD. Myocardial infarction in young patients. Am J Med. 1999 Sep;107(3):254-61. https://doi.org/10.1016/S0002-9343(99)00218-1

14. Adhikari C, Manandhar R, Prajapati D, et al. Acute ST-Elevation Myocardial Infarction in Young in Shahid Gangalal National Heart Centre, Kathmandu, Nepal. J Adv Intern Med. 2017 Nov 6;6(2 SE-Original Articles). https://doi.org/10.3126/jaim.v6i2.18538

15. Gautam MP, Sogunuru G, Subramanyam G, et al. Acute coronary syndrome in an intensive care unit of a tertiary care centre: the spectrum and coronary risk factors. JNMA J Nepal Med Assoc. 2013;52(190):316-21. https://doi.org/10.31729/jnma.1897

16. Shreshta N, Basnet S, Bhandari R, et al. Presentation and outcome of patients with acute coronary syndromes in eastern Nepal. Swiss Med Wkly. 2011 Apr 13;141:1-6. https://doi.org/10.4414/smw.2011.13174

17. Misiriya KJR, Sudhayakumar N, Khadar SA, et al. The clinical spectrum of acute coronary syndromes: experience from a major center in Kerala. J Assoc Physicians India. 2009 May;57:377-83.

http://www.ncbi.nlm.nih.gov/pubmed/19634283
18. Singh PS, Singh G, Singh SK. Clinical profile and risk factors in acute coronary syndrome. J Ind Acad of Clin Med.2013;14(2):130-2.

19. Adhikari G, Baral D. Clinical profile of patients presenting with acute myocardial infarction. Int J Adv Med. 2018;5:22833. https://doi.org/10.18203/2349-3933.ijam 20181068

20. Vaidya C, Majmudar D. A study of acute ST elevation myocardial infarction in young patients from government teaching hospital. Sudan Med Monit. 2015 Apr 1;10(2):45. https://doi.org/10.4103/1858-5000.160939

21. Yadav P, Joseph D, Joshi P, et al. Clinical profile \& risk factors in acute coronary syndrome. Natl J Comm Med. 2010;1(2):150-1.

http://www.njcmindia.org/home/abstrct/63/\#

22. Pathak V, Ruhela M. In hospital complications and outcomes in acute ST elevation MI patients at a tertiary care Centre in North India. J indian Coll Cardiol. 2015;5(2):112-8. https://doi.org/10.1016/j.jicc.2015.02.003

23. Kundu SC, Bhattacharjee TD, Banerjee D, et al. Profile of myocardial infarction among the railroad workers in Eastern India-a 6-year study. Indian Heart J. 1982;34(3):151-5.

24. Fox KAA, Goodman SG, Klein W, et al. Management of acute coronary syndromes. Variations in practice and outcome. Findings from the Global Registry of Acute Coronary Events (GRACE). Eur Heart J. 2002 Aug 1;23(15):1177-89. https://doi.org/10.1053/euhj.2001.3081 